\title{
Investigation of surface properties in turn milling of particle-reinforced aluminium matrix composites using MCD-tipped tools
}

\author{
Benjamin Clauß ${ }^{1} \cdot$ Andreas Nestler $^{1} \cdot$ Andreas Schubert $^{1} \cdot$ Dagmar Dietrich $^{2} \cdot$ Thomas Lampke $^{2}$
}

Received: 25 March 2019 / Accepted: 17 July 2019 / Published online: 21 August 2019

(C) The Author(s) 2019

\begin{abstract}
Aluminium matrix composites (AMCs) consist of a comparably soft matrix alloy which is typically reinforced with at least one ceramic component such as fibres, whiskers, or particles. The additional ceramic components allow improved material properties but result in an increased tool wear in machining. Furthermore, the reinforcements lead to the generation of surface imperfections on the generated surface. The investigations aim for low roughness values, reduced surface imperfections, and strong compressive residual stresses. It is assumed that a combination of these properties benefits an improved fatigue behaviour. Turn milling experiments with single-edged monocrystalline diamond (MCD)-tipped tools are carried out to examine the influence of the cutting parameters and different clearance angles. The generated surfaces are evaluated considering roughness, porosity, and residual stress state. Additionally, the microstructure of the surface layer is analysed. In the investigated range, a cutting speed of $200 \mathrm{~m} / \mathrm{min}$, an axial feed of $1 \mathrm{~mm}$, and a feed per tooth of $0.1 \mathrm{~mm}$ result in a reduced formation of surface imperfections. Moreover, using a tool with a clearance angle of $1^{\circ}$ leads to smaller roughness values $\mathrm{Rz}$ and a lower valley void volume $\mathrm{Vvv}$ compared with a clearance angle of $5^{\circ}$ for all combinations investigated. For all experiments, the generation of compressive residual stresses in the surface layer is observed. Higher absolute values of the compressive residual stresses are benefited by a reduced axial feed. EBSD analyses indicate that the grain structure in the surface layer is refined as a consequence of the cutting process. The research provides fundamentals in finishing of particle-reinforced AMCs by turn milling. A better understanding of the interaction between the cutting process and the surface properties is acquired.
\end{abstract}

Keywords Aluminium matrix composite $\cdot$ Cutting $\cdot$ MCD $\cdot$ Surface properties $\cdot$ Turn milling

\section{Introduction}

\subsection{Technical and economical significance of AMCs}

The development of modern technical systems involves an ongoing demand for improved performance and efficiency. Trying to meet these requirements, lightweight strategies are

Benjamin Clauß

benjamin.clauss@mb.tu-chemnitz.de

1 Chemnitz University of Technology, Professorship Micromanufacturing Technology, Reichenhainer Str. 70, 09126 Chemnitz, Germany

2 Chemnitz University of Technology, Materials and Surface Engineering Group, Erfenschlager Str. 73, 09125 Chemnitz, Germany applied. In addition to approaches concerning the structural lightweight design and the system lightweight design, the development of advanced materials with adapted properties is of major importance.

Singh, Chaitanya, and Kumar [1] addressed the topic of metal matrix composites (MMCs) from an engineering, manufacturing, and machining point of view. The high relevance of the composites due to a high specific strength and a beneficial behaviour at elevated temperatures is pointed out. The matrix is commonly represented by aluminium alloys, titanium alloys, and others. Particlereinforced MMCs typically using $\mathrm{SiC}$ or $\mathrm{Al}_{2} \mathrm{O}_{3}$ particles enable a higher isotropy of the mechanical properties compared with fibre-reinforced composites. Accordingly, they are researched more extensively.

Schmidt et al. [2] investigated the economic potentials of AMCs as a substitution for unreinforced aluminium alloys 
for lightweight applications in aerospace industry using a technology, user, and market analysis and forecast. Taking the aeronautic sector into account, a promising cumulative market potential of Airbus and Boeing of about $\$ 160$ billion in 2016 is identified. Appropriate machining solutions are emphasised as a key component for a successful transfer into industrial applications.

Di Ilio and Paoletti [3] examined manufacturing and machining aspects of MMCs. Improvements concerning castability and formability of MMCs enable enhanced nearnet shape manufacturing. Nonetheless, it is concluded that finishing operations by cutting can typically not be omitted.

\begin{tabular}{|c|c|}
\hline $\begin{array}{l}\text { Nomenclature } \\
\text { Symbol }\end{array}$ & Definition \\
\hline$a_{\mathrm{p}}$ & Depth of cut \\
\hline$A_{\mathrm{g}}$ & Uniform elongation \\
\hline AMC & Aluminium matrix composite \\
\hline $\mathrm{CBN}$ & Cubic boron nitride \\
\hline $\mathrm{CI}$ & Confidence index \\
\hline CVD & Chemical vapour deposition \\
\hline$d_{\mathrm{g}}$ & Grain diameter \\
\hline$d_{\mathrm{T}}$ & Tool diameter \\
\hline$d_{\mathrm{Wp}}$ & Workpiece diameter \\
\hline$E$ & Young's modulus \\
\hline EBSD & Electron backscatter diffraction \\
\hline$f_{\mathrm{ax}}$ & Axial feed \\
\hline$f_{\mathrm{Z}}$ & Feed per tooth \\
\hline HSS & High speed steel \\
\hline$H V$ & Vickers hardness \\
\hline MCD & Monocrystalline diamond \\
\hline MMC & Metal matrix composite \\
\hline$n_{\mathrm{Sp}}$ & Spindle speed \\
\hline$n_{\mathrm{Wp}}$ & Rotational speed of the workpiece \\
\hline PCD & Polycrystalline diamond \\
\hline QBSD & Quadrant backscatter electron detector \\
\hline $\mathrm{Ra}$ & Arithmetic mean roughness \\
\hline$r_{\mathrm{n}}$ & Cutting edge radius \\
\hline$R_{\mathrm{m}}$ & Ultimate tensile strength \\
\hline$R_{\mathrm{p} 0.2}$ & Yield strength \\
\hline $\mathrm{Rz}$ & Surface roughness depth \\
\hline SE & Secondary electron \\
\hline SEM & Scanning electron microscopy \\
\hline$v_{\mathrm{c}}$ & Cutting speed \\
\hline$v_{\mathrm{f}, \mathrm{ax}}$ & Axial feed rate \\
\hline VB & Flank wear land width \\
\hline Vvv & Valley void volume \\
\hline$z$ & Number of teeth \\
\hline$\alpha_{\mathrm{o}}^{\prime}$ & $\begin{array}{l}\text { Clearance angle of } \\
\text { the minor cutting edge }\end{array}$ \\
\hline$\gamma_{\mathrm{o}}^{\prime}$ & $\begin{array}{l}\text { Rake angle of } \\
\text { the minor cutting edge }\end{array}$ \\
\hline$\varepsilon_{\mathrm{r}}$ & Tool included angle \\
\hline
\end{tabular}

\begin{tabular}{ll}
\hline$\kappa_{\mathrm{r}}^{\prime}$ & $\begin{array}{l}\text { Tool cutting edge angle of } \\
\text { the minor cutting edge }\end{array}$ \\
$\lambda$ & Ratio of rotational speeds \\
$\lambda_{\mathrm{c}}$ & Cut-off wavelength \\
$\lambda_{\mathrm{s}}$ & Denoising wavelength \\
$v$ & Poisson's ratio \\
$\sigma_{\mathrm{RS}, \mathrm{I}}$ & First principal residual stress
\end{tabular}

\subsection{Cutting materials for AMC machining}

The presence of hard ceramic particles leads to significant challenges in the machining processes. The tool wear is substantially increased, with abrasion as predominant wear mechanism. Accordingly, there is a certain limitation of cutting tool materials, enabling controlled machining conditions by sufficient wear resistance.

Hung et al. [4] investigated the machining of aluminium wrought and cast alloys reinforced with about 20 percent by volume of $\mathrm{SiC}$ particles. The appropriateness of highspeed steels (HSS), cemented carbides, cubic boron nitride $(\mathrm{CBN})$, and polycrystalline diamond (PCD) was examined. Compared with the super hard cutting materials, HSS and cemented carbides reached the end of tool life significantly earlier. PCD provided the highest wear resistance.

Yanming and Zehua [5] investigated the turning a 15 percent by weight $\mathrm{SiC}$ particle-reinforced aluminium cast alloy A356 with different particle sizes. For the experiments HSS, uncoated and coated cemented carbides, different cutting ceramics, CBN and PCD were applied. Eventually, it is concluded that cutting materials with a higher hardness compared with the reinforcing $\mathrm{SiC}$ particles are necessary when machining AMCs.

Ding, Liew, and Liu [6] studied the tool performance when machining a 20 percent by volume SiC particlereinforced aluminium cast alloy using several commercially available and experimental CBN grades as well as PCD. The outcome shows that PCD is more appropriate when machining the AMC due to superior hardness compared with the investigated CBN grades. In addition to a higher abrasion and fracture resistance provided by PCD, the research shows a reduced tendency to adhesion and built-up edge formation.

Collins and Cook [7] investigated the wear behaviour of tools tipped with two different PCD grades, electrically conductive and non-conductive chemical vapour deposition (CVD) diamond, and MCD when turning a 20 percent by volume SiC particle-reinforced aluminium alloy comparable with AA2618. The tool wear is characterised predominantly by abrasive mechanisms affected by the ratio of the hardness values of the SiC particles and the cutting material. Tribo-thermal or tribo-chemical mechanisms are less relevant. An increased diamond particle size enhances the wear 
resistance entailing a higher potential of synthesised MCD and CVD diamond compared with PCD, when machining AMCs.

Cooper et al. [8] investigated the wear resistance of different PCD grades, polycrystalline and monocrystalline CVD diamond, and natural diamond (ND), when machining an aluminium wrought alloy AA2124 reinforced with SiC particles of averaged sizes of $3 \mu \mathrm{m}$ and $20 \mu \mathrm{m}$ and a fraction of 25 percent by volume as well as particles with a size of $3 \mu \mathrm{m}$ and a volume fraction of $40 \%$. Finegrained PCD provided lower wear resistance compared with polycrystalline CVD diamond and PCD with a multimodal grain size. Comparing ND and monocrystalline CVD diamond, there is a comparable very low wear progression when machining AMCs with 25 percent by volume $\mathrm{SiC}$ particles. However, when turning AMCs with a 40 percent by volume fraction the monocrystalline CVD diamond provides an increased tool life of about $40 \mathrm{~min}$ longer compared with ND.

\subsection{Hybrid machining of MMCs}

The most relevant hybrid cutting processes for MMCs are represented by laser- and vibration-assisted machining. These are typically applied to improve the machinability of the composites.

Bejjani et al. [9] investigated laser-assisted turning of a 10 to $12 \%$ by weight $\mathrm{TiC}$ particle-reinforced titanium wrought alloy TiAl6V4. Using PCD-tipped tools combined with laser-assistance, the total cut volume was significantly increased up to $180 \%$ compared with unassisted cutting.

Dandekar and Shin [10] investigated the laser-assisted machining (LAM) of a 20 percent by volume particlereinforced aluminium cast alloy A359. According to the findings, a $37 \%$ reduction of the surface roughness values is achieved with laser assistance.

Przestacki [11] investigated turning of a 20 percent by volume $\mathrm{SiC}$ particle-reinforced aluminium cast alloy AlSi9Mg using cemented carbide and $\mathrm{CBN}$ as cutting materials. For both cutting materials, the tool wear is significantly reduced applying additional laser-assistance. Applying cemented carbide in laser-assisted cutting with a power of $1000 \mathrm{~W}$, the most significant reduction of the tool wear of about $37 \%$ is achieved.

Przestacki and Jankowiak [12] investigated the surface properties in laser-assisted machining of a 20 percent by volume $\mathrm{SiC}$ particle-reinforced aluminium cast alloy AlSi9Mg. The application of laser-assistance with a power of $600 \mathrm{~W}$ enabled a reduction of the surface roughness values of about $30 \%$ compared with conventional turning.

Nestler and Schubert [13] investigated the ultrasonic vibration-assisted turning of a 25 percent by volume $\mathrm{SiC}$ particle-reinforced aluminium wrought alloy using CVD diamond-tipped tools. The most significant effects were obtained with ultrasonic vibration assistance in the radial direction leading to the generation of characteristic surface structures. The resulting surface roughness values increased with rising vibration amplitudes.

Xiang et al. [14] examined ultrasonic vibration-assisted milling of a 65 percent by volume $\mathrm{SiC}$ particle-reinforced AMC. According to the results, ultrasonic vibration assistance led to lower surface roughness values and a reduced formation of surface imperfections depending on the applied cutting parameters. The main reason was considered with reduced contact times and friction between tool, chip, and generated surface.

Zhi, Xiang, and Deng [15] addressed ultrasonic vibration-assisted milling using a PCD-tipped tool. The AMC was reinforced with 65 percent by volume of SiC particles. According to the researchers, ultrasonic vibration in the direction of passive force benefits an increased proportion of SiC particles being cut-through compared with being smashed during tool contact in conventional milling.

\subsection{Surface properties in AMC machining}

In addition to increased tool wear in AMC machining, the microscopically heterogeneous structure of these composites affects the properties of the generated surface. The ceramic reinforcements can lead to surface imperfections like voids, cracks, or fractured particles whereas the comparably soft matrix tends to the formation of protuberances on the generated surfaces. Furthermore, in case of lightweight designs, both high static and dynamic strength are of increasing importance. Accordingly, the surface properties represented by roughness, surface imperfections, and the physical properties of the surface layer are important when machining AMCs.

Dabade et al. [16] investigated turning of a 10 and 30 percent by volume $\mathrm{SiC}$ particle-reinforced aluminium wrought alloy AA2214 using CBN-tipped indexable inserts with and without wiper edges. The findings indicate that using a tool with a wiper edge allows a significant reduction of the feed marks as well as a reduced formation of pits and cracks on the generated surface. Additionally, tools with wiper edges result in stronger compressive residual stresses in the generated surface layer.

Bushan, Kumar, and Das [17] addressed turning of an unreinforced and a 10 percent by weight $\mathrm{SiC}$ particlereinforced aluminium wrought alloy AA7075 with average particle sizes of 20 to $40 \mu \mathrm{m}$ using a PCD-tipped tool. The influence of the cutting parameters on the surface microstructure was evaluated based on cutting experiments. The findings show that an increase of the cutting speed keeping the remaining cutting parameters unchanged leads to reduced roughness values $\mathrm{R} a$. However, the combined 
increase of feed and depth of cut with constant cutting speed results in higher roughness values.

$\mathrm{Ge}, \mathrm{Xu}$, and $\mathrm{Fu}$ [18] investigated milling of an unreinforced and a $20 \%$ SiC particle-reinforced aluminium alloy AA2009 with PCD-tipped tools. The machining of the composite leads to surface imperfections in the form of voids, scales, and scratches on the generated surface. Moreover, an affected surface layer with a thickness of about $20 \mu \mathrm{m}$ to $35 \mu \mathrm{m}$ occurs. The maximum of the micro hardness values is determined in a distance of about $20 \mu \mathrm{m}$ from the generated surface.

Dong et al. [19] researched high-speed milling of a 45 percent by volume $\mathrm{SiC}$ particle-reinforced aluminium alloy with an average particle size of $3 \mu \mathrm{m}$ using PCDtipped tools. Addressing the influence of selected cutting parameters on the surface properties, an increased cutting speed as well as a higher feed leads to formation of deeper surface imperfections. It is suggested that the formation of deep voids results from different superimposed effects, comprising particle pull-out as well as the generation of subsurface voids within the surface layer.

Wang et al. [20] focused on the milling of an unreinforced and a 65 percent by volume $\mathrm{SiC}$ particle-reinforced aluminium wrought alloy AA6063 using PCD-tipped tools. The investigations addressed the influence of cutting speed, feed per tooth, and depth of cut on the surface roughness values $\mathrm{Ra}$ and the residual stress state of the generated surface. The findings indicate raising roughness values when machining the AMC, increasing with a higher feed per tooth, and decreasing with an increased cutting speed. Cutting the unreinforced matrix alloy leads to tensile residual stresses whereas machining of the AMC results in the generation of compressive residual stresses.

Schubert et al. [21] investigated the machining of a 25 percent by volume $\mathrm{SiC}$ particle-reinforced aluminium wrought alloy AA2124 with an average particle size of 2 to $5 \mu \mathrm{m}$ in T4 heat treament. The influence of different feed values was investigated using CVD diamondtipped indexable inserts with chip breakers, different corner geometries and wiper edges. It is indicated that chip breakers enable improvements of the surface roughness depending on the cutting parameters. Tools with a small corner radius benefit reduced surface imperfections, mainly attributed to higher compressive stresses in the cutting zone. The application of inserts with a wiper edge facilitates reduced surface roughness values, but does not decrease the number of flaws.

Schubert and Nestler [22] examined a modified cutting corner geometry in turning of a 25 percent by volume SiC particle-reinforced aluminium wrought alloy AA2124 with an average $\mathrm{SiC}$ particle size of 2 to $3 \mu \mathrm{m}$ using CVD diamond-tipped tools. Addressing surface roughness and imperfections, the application of tools with a wiper edge or trailing edges enable reduced $\mathrm{Rz}$ values being determined by the edge quality as well. It is indicated that tools with a flank wear land width of about $100 \mu \mathrm{m}$ allow a significantly reduced generation of surface imperfections.

Clauß, Nestler, and Schubert [23] examined milling of a 10 percent by volume $\mathrm{SiC}$ particle-reinforced powder metallurgically produced aluminium wrought alloy comparable to EN AW-2017 with an average SiC particle size below $2 \mu \mathrm{m}$ using a CVD diamond-tipped tool. The influence of cutting speed and feed per tooth on surface structure and the physical properties of the generated surface was addressed. An increased cutting speed on average leads to a reduced void formation. Machining, with a cutting speed of $200 \mathrm{~m} / \mathrm{min}$ and a feed per tooth of $0.015 \mathrm{~mm}$, enables strongly increased compressive residual stresses compared with the initial state.

Ge et al. [24] investigated the ultra-precision machining of a 5,10 , or 15 percent by volume of $\mathrm{SiC}$ particlereinforced aluminium cast alloy A356 with an average SiC particle size of $15 \mu \mathrm{m}$ and a 15 and 25 percent by volume $\mathrm{SiC}$ particle-reinforced aluminium wrought alloy AA2024 with an average particle size of $4 \mu \mathrm{m}$ using MCDand PCD-tipped tools. Focusing on the surface structure and the hardness in the surface layer, machining with an increased feed leads to a more distinct generation of surface imperfections. Applying PCD-tipped tools, the thickness of the affected surface layer with increased microhardness is thicker compared with MCD-tipped tools. Nonetheless, the highest increase of microhardness results when using MCD as cutting material.

Bian et al. [25] investigated high-precision milling of a 65 percent by volume $\mathrm{SiC}$ particle-reinforced aluminium alloy with an average SiC particle size of 60 to $80 \mu \mathrm{m}$ using MCD-tipped tools. Addressing the transition between brittle and ductile mode, when cutting the $\mathrm{SiC}$ particles, the cutting speed is kept unchanged, while feed per tooth and depth of cut were varied in a range of several microns. The results indicate that a feed per tooth of $1 \mu \mathrm{m}$ combined with a depth of cut of $2 \mu \mathrm{m}$ result in a value for $\mathrm{Ra}$ of $0.078 \mu \mathrm{m}$. However, the generated surface still features imperfections based on particle pull-out and fragmentation.

Examining the particle separation areas, to some extent smooth cutting sections are found, indicating cutting in ductile mode.

Referring to the application of AMCs, there is also high relevance of non-circular parts. In this context, turn milling offers a suitable method for fundamental research in machining of advanced materials. The kinematics synthesised from turning and milling allows to transfer fundamental results to non-circular geometries comparably easy.

Schubert, Funke, and Nestler [26] investigated turn milling of a 15 percent by volume $\mathrm{Al}_{2} \mathrm{O}_{3}$ particle-reinforced aluminium wrought alloy AA2017 with an average SiC particle 
size of $200 \mathrm{~nm}$ to $2 \mu \mathrm{m}$ using a CVD diamond-tipped tool. The results indicate that the tool characterised by a cutting edge angle of the minor cutting edge $\kappa_{\mathrm{r}}^{\prime}$ of about $0^{\circ}$ enables generated surfaces with Ra values of about $0.16 \mu \mathrm{m}$.

\subsection{Inferences}

Based on the state of the art, the research should focus the machining of a $\mathrm{SiC}$ particle-reinforced aluminium alloy using a MCD-tipped tool to improve the wear resistance against the abrasive $\mathrm{SiC}$ particles. The influence of a modified cutting tool geometry on the surface properties should be subjected to detailed investigations. Turn milling should be focused to encourage the machining of non-circular workpieces manufactured from advanced lightweight materials.

\section{Fundamentals of cylindrical turn milling}

Turn milling represents a machining process with geometrically defined cutting edges. It can be defined as a combination of turning and milling. Thus, characteristics of both processes result in a more complex kinematics. The different variants of cylindrical turn milling are illustrated according to Fig. 1. If the axes of a tool and workpiece are aligned perpendicular, an orthogonal turn milling process is given. In this case, the generated surface of the workpiece is produced by the minor cutting edges and the cutting corners. If there is no intersection of the axes, the process is defined as eccentrical orthogonal turn milling. In case of tangential turn milling, the orthogonal alignment of the axes remains, yet the generated surface is produced primarily by the major cutting edges of the tool. With both axes being aligned parallel an axial turn milling process occurs.

In difference to a turning process the cutting speed $v_{\mathrm{c}}$ results from the rotation of the tool. It can be determined according to equation:

$v_{\mathrm{c}}=\pi \cdot d_{\mathrm{T}} \cdot n_{\mathrm{Sp}}$

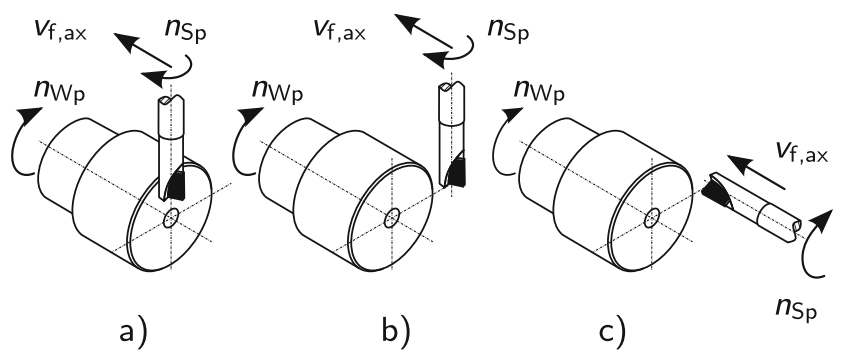

Fig. 1 Fundamental kinematics of (a) orthogonal turn milling, (b) tangential turn milling, and (c) axial turn milling
Moreover, the process is characterised by two separate feeds due to the workpiece rotation and an additional linear relative motion between the milling spindle and the workpiece. The axial feed is defined with reference to the rotation of the workpiece, comparable with turning. With a defined axial feed, the feed rate in the axial direction can be determined according to

$v_{\mathrm{f}, \mathrm{ax}}=f_{\mathrm{ax}} \cdot n_{\mathrm{Wp}}$.

The feed per tooth results from the number of cuts of the tool per revolution of the workpiece, respecting the actual workpiece diameter. The specific value of the required rotational speed of the workpiece is determined depending on the ratio of the rotational speeds of the workpiece and the milling spindle according to Eq. 3 .

$$
\begin{aligned}
f_{\mathrm{z}} & =\frac{\pi \cdot\left(d_{\mathrm{Wp}}-2 \cdot a_{p}\right) \cdot n_{\mathrm{Wp}}}{z \cdot n_{\mathrm{Sp}}} \\
n_{\mathrm{Wp}} & =\frac{f_{\mathrm{z}} \cdot z \cdot n_{\mathrm{Sp}}}{\pi \cdot\left(d_{\mathrm{Wp}}-2 \cdot a_{\mathrm{p}}\right)}
\end{aligned}
$$

Accordingly, the workpiece diameter is reduced by twice the depth of cut $a_{\mathrm{p}}$ to take the actual diameter of the generated surface into consideration. Rearranging to $n_{\mathrm{Wp}}$ the required value of the workpiece rotational speed can be determined. This is appropriate because the surface structure resulting from the effective feed per tooth on the generated surface is of major interest.

\section{Material and methods}

For the experiments, a commercially available AMC is used, consisting of the aluminium wrought alloy AA2124 as matrix. As reinforcement, $\mathrm{SiC}$ particles with an average particle size of 2 to $3 \mu \mathrm{m}$ and a volume proportion of $25 \%$ are applied. The composite is produced using a powder metallurgical route. Subsequent to high-energy mixing of all components, the powder is compacted and pressed hot isostatically to enhance the mechanical properties. The material is extruded with an extrusion ratio of approximately 50:1. Eventually, a T4 heat treatment is applied. Table 1 presents the averaged specific values of

Table 1 Mechanical properties of the AMC used

\begin{tabular}{ll}
\hline Mechanical parameter & Value \\
\hline Yield strength $R_{\mathrm{p} 0.2}$ & $513 \mathrm{MPa}$ \\
Ultimate tensile strength $R_{\mathrm{m}}$ & $699 \mathrm{MPa}$ \\
Young's modulus $E$ & $117 \mathrm{GPa}$ \\
Uniform elongation $A_{\mathrm{g}}$ & $4.6 \%$ \\
Vickers hardness $H V$ & $223 \mathrm{HV} 10$
\end{tabular}


Fig. 2 Cross-section of the AMC used in the longitudinal direction as (a) SE image and (b) QBSD image

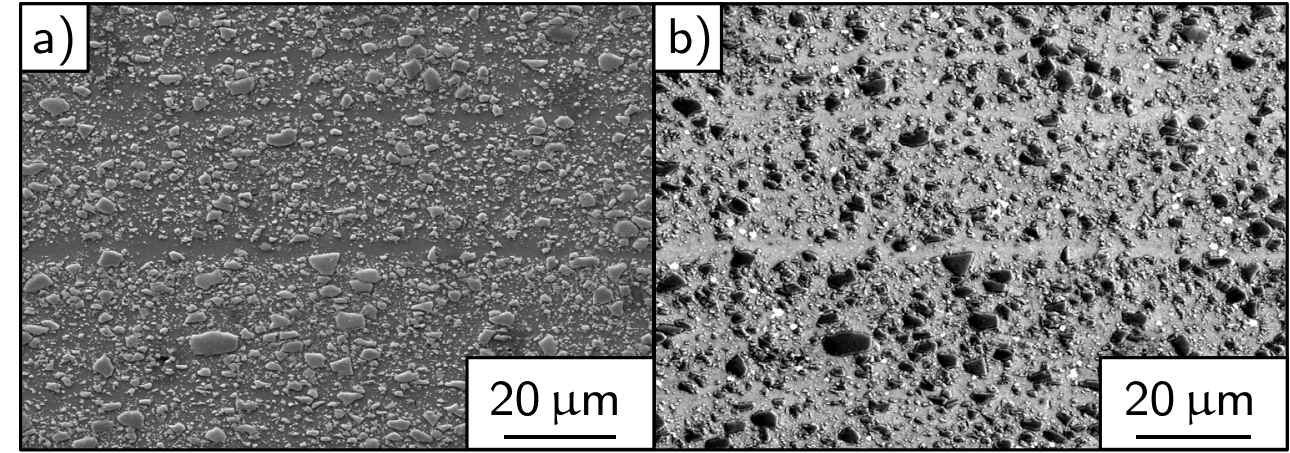

the most relevant mechanical properties in the direction of extrusion (except hardness values).

Figure 2 displays a cross-section of the AMC used in the longitudinal direction, representing the direction of extrusion as well. In order to provide a detailed insight into the microstructure of the investigated composite, the crosssection is presented as secondary electrons (SE) as well as quadrant backscattered electron detector (QBSD) image.

There is a comparably homogeneous distribution of the particles. However, in the longitudinal direction, banding effects occur. This is attributed to the extrusion process, thus leading to an increased anisotropy of the mechanical properties.

The specimen geometry is represented by a cylindrical part that provides a diameter of $22 \mathrm{~mm}$ over a length of $15 \mathrm{~mm}$ being machined in the cutting experiments. At the end of that section, a relief is integrated to allow appropriate tool positioning and to prevent collision between the tool and the device. The clamping interface provides a diameter of $18 \mathrm{~mm}$.

For the experiments, single-edged MCD-tipped tools are used with a diameter of $6 \mathrm{~mm}$. Moreover, a tool geometry with a rake angle of the minor cutting edge $\gamma_{0}^{\prime}$ of $0^{\circ}$, a cutting edge angle of the minor cutting edge $\kappa_{\mathrm{r}}^{\prime}$ of $0^{\circ}$, and a tool included angle $\varepsilon_{\mathrm{r}}$ of $90^{\circ}$ is applied. The cutting corner features a chamfer of $0.1 \mathrm{~mm} \times 45^{\circ}$ to achieve a higher stability and wear resistance. Depending on the specific

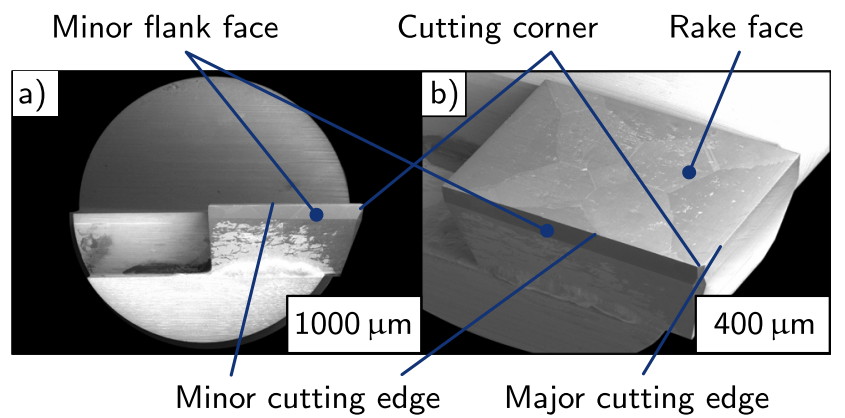

Fig. 3 Cutting tool geometry. (a) Minor cutting edge and minor flank face, (b) Cutting corner, minor cutting edge, major cutting edge, and rake face combination of cutting parameters, tools with clearance angles of the minor cutting edge $\alpha_{0}^{\prime}$ of $1^{\circ}$ and $5^{\circ}$ are applied. Figure 3 presents scanning electron microscopy (SEM) images illustrating one of the tools used.

Figure 3 provides an overview of the cutting part for one of the MCD-tipped tools used throughout the experimental investigations. Complementary, Fig. 4 enables a more detailed view onto the major cutting edge, the minor cutting edge, and the cutting corner of the tool before machining.

The experiments are realised using one tool of each type with the specified clearance angles of $1^{\circ}$ or $5^{\circ}$. Based on SEM images, the cutting edge radii are qualitatively determined below $1 \mu \mathrm{m}$ for the tools used. Cutting edge chipping is not determinable.

The turn milling tests are carried out on a highprecision milling centre of the type KERN Pyramid Nano. The specimens are clamped using a collet chuck system. Figure 5 presents the experimental setup used for the investigations.

In the experimental investigations, the cutting parameters are varied using a fractional experimental design. It is intended to identify the influence on the surface microstructure, the residual stress state, and the microstructure of the surface layer. The cutting speed $v_{\mathrm{c}}$ is defined with $100 \mathrm{~m} / \mathrm{min}, 200 \mathrm{~m} / \mathrm{min}$, and $400 \mathrm{~m} / \mathrm{min}$. The axial feed $f_{\mathrm{ax}}$ is investigated for values of $1 \mathrm{~mm}, 2 \mathrm{~mm}$, and $3 \mathrm{~mm}$. Additionally, the feed per tooth $f_{\mathrm{z}}$ comprises values of $0.1 \mathrm{~mm}$, $0.2 \mathrm{~mm}$, and $0.3 \mathrm{~mm}$. The depth of cut is kept unchanged

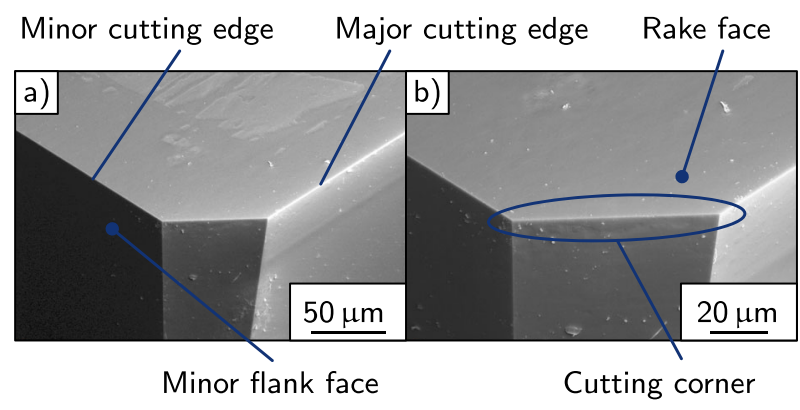

Fig. 4 Detailed geometry of the cutting part. (a) Major cutting edge, minor cutting edge, and flank faces. (b) Cutting corner and rake face 


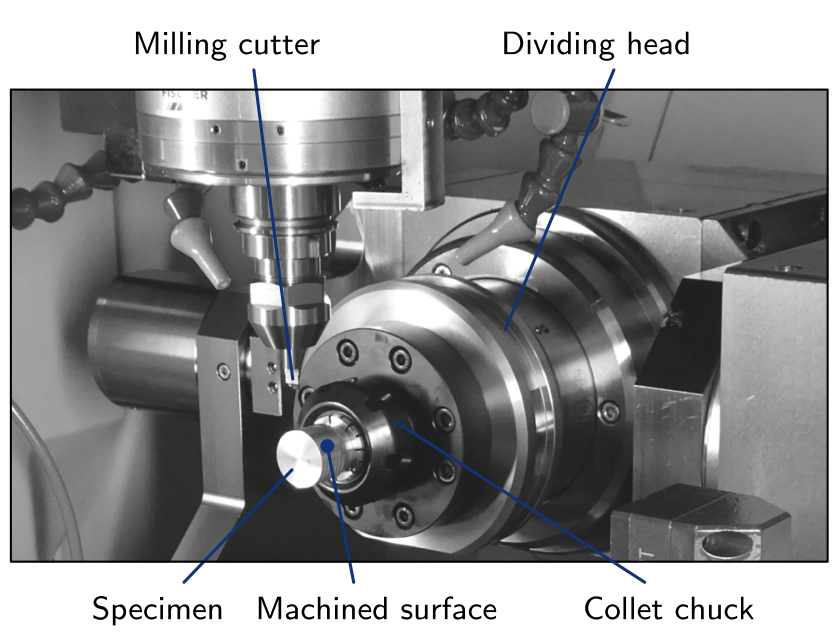

Fig. 5 Experimental setup in turn milling

with $0.2 \mathrm{~mm}$ for all experiments. The cutting tests are realised in down milling using flood cooling based on emulsion as cooling lubricant. The statistical reliability of the results is enhanced by repeating each combination of process parameters in three experiments. Table 2 summarises the investigated combinations of cutting parameters and clearance angles.

Figure 6 illustrates the applied evaluation methods with reference to the specimen geometry used for the investigations.

The generated surfaces are evaluated applying quantitative as well as qualitative methods. The necessary surface data are gathered using a tactile roughness measurement device of the type Mahr LD 120. First of all, the primary profiles are processed applying a denoising wavelength $\lambda_{\mathrm{s}}$

Table 2 Investigated combinations of cutting parameters and clearance angle

\begin{tabular}{llll}
\hline $\begin{array}{l}v_{\mathrm{c}} \\
(\mathrm{m} / \mathrm{min})\end{array}$ & $\begin{array}{l}f_{\mathrm{z}} \\
(\mathrm{mm})\end{array}$ & $\begin{array}{l}f_{\mathrm{ax}} \\
(\mathrm{mm})\end{array}$ & $\alpha_{\mathrm{o}}^{\prime}$ \\
\hline 100 & 0.2 & 2 & $1^{\circ}$ \\
200 & 0.2 & 2 & $1^{\circ}$ \\
400 & 0.2 & 2 & $1^{\circ}$ \\
200 & 0.1 & 2 & $1^{\circ}$ \\
200 & 0.3 & 2 & $1^{\circ}$ \\
200 & 0.2 & 1 & $1^{\circ}$ \\
200 & 0.2 & 3 & $1^{\circ}$ \\
100 & 0.2 & 2 & $5^{\circ}$ \\
200 & 0.2 & 2 & $5^{\circ}$ \\
400 & 0.2 & 2 & $5^{\circ}$ \\
200 & 0.1 & 2 & $5^{\circ}$ \\
200 & 0.3 & 2 & $5^{\circ}$ \\
200 & 0.2 & 1 & $5^{\circ}$ \\
200 & 0.2 & 3 & $5^{\circ}$ \\
\hline
\end{tabular}

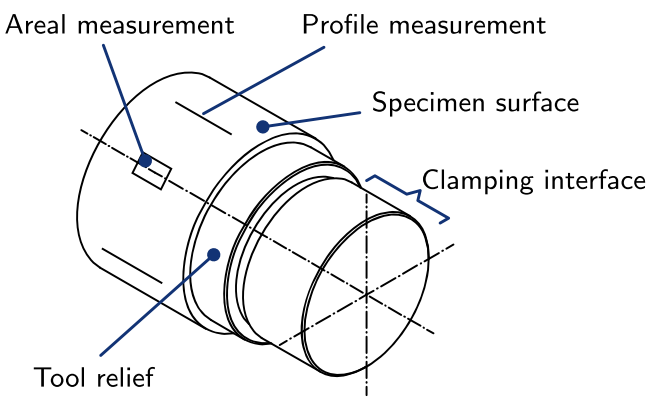

Fig. 6 Evaluation methods used with reference to the specimen geometry

of $2.5 \mu \mathrm{m}$ and a cut-off wavelength $\lambda_{\mathrm{c}}$ of $0.8 \mathrm{~mm}$ resulting in a required measuring length of the roughness profile of $4 \mathrm{~mm}$ and a traversed length of $5.6 \mathrm{~mm}$. For each specimen, three profile measurements are realised, equally spaced over the perimeter of the specimen.

Moreover, the same measurement system with an additional cross table is used for tactile areal measurements of selected surfaces. In this context, the 3D data are generated from 2001 single roughness profiles with a traversed length of the measured area of $5 \mathrm{~mm}$, an effective measuring length of $4 \mathrm{~mm}$ as well as a traversed width of $2 \mathrm{~mm}$. The distance between the single measurement points in the measuring direction is $0.5 \mu \mathrm{m}$, providing an appropriate resolution. The distance of adjacent traces is $1 \mu \mathrm{m}$. With the gathered data represented by point clouds, 3D embodiments of the generated surfaces are obtained by sorting and arranging the data points according to their coordinates and height information. The areal measurements are subsequently assessed using the evaluation software MountainsMap ${ }^{\circledR}$.

Subsequently, based on these 3D data, the generated surfaces are evaluated to determine functional surface parameters using the mentioned evaluation software. The main aim is to achieve a method enabling the quantification of the void formation. However, not only the number but also the depth, the area, and thus the volume of the voids has to be respected. Accordingly, one suitable strategy is seen in the quantification of voids in the generated surfaces using the valley void volume Vvv. Referring to that, an appropriate preparation of the surface data is required to ensure reliability.

First of all, the traversed surface is pruned to the required dimensions of $4 \mathrm{~mm} \times 2 \mathrm{~mm}$ and levelled using a subtraction method. In a second step, the cylindrical shape of the specimen surface is compensated and levelled using a second-degree polynomial filter. Additionally, the waviness is separated by applying a filter with a cut-off wavelength of $25 \mu \mathrm{m}$. The cut-off filter approximates the tenfold size of the structures of interest, represented by the averaged estimated size of the voids according to the particle size. Furthermore, 


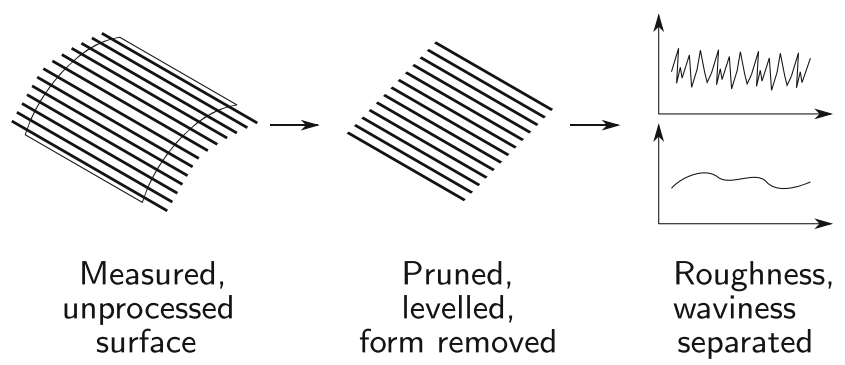

Fig. 7 Schematic of surface data processing for the evaluation of the Vvv parameter

on the generated surfaces, kinematic marks result from subsequent cuts with a distance equal to the feed per tooth $f_{\mathrm{z}}$ and the specific micro geometry of the cutting edge. These are removed by aligning the surface column by column in the direction of the axial feed, based on the least squares method. Eventually, there is an additional levelling process preliminary to the evaluation of the $\mathrm{Vvv}$ parameter. Figure 7 schematically presents the main steps in data processing.

The characterisation of the residual stress state in the matrix alloy is based on $\mathrm{X}$-ray diffraction analysis of the generated surfaces. The measurements are realised according to $\sin ^{2} \psi$-method, using a diffractometer of the type Siemens D5000. The residual stresses are determined based on the measurement of the diffraction angle due to deformation of the lattice structure respecting crystallographic planes of the type $\{420\}$ according to Fig. 8 . In this context, the elastic parameters are defined with Young's modulus $E=69 \mathrm{GPa}$ and Poisson's ratio of $v=$ 0.35 . Furthermore, a measuring field with a diameter of $2 \mathrm{~mm}$ is applied.

The identification of possible influences of the machining process on the microstructure of the surface layer is

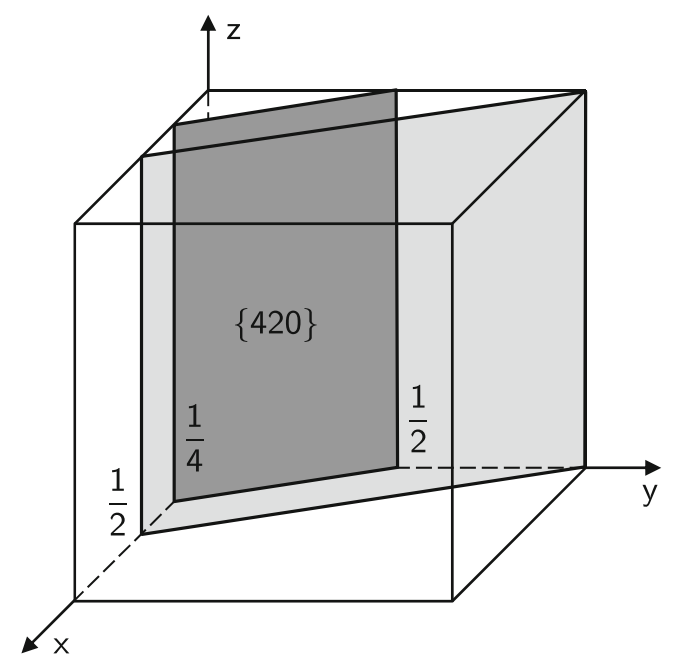

Fig. 8 Crystallographic planes $\{420\}$ considered for residual stress evaluation achieved by EBSD analysis. In this context, a sufficient preparation of the specimens strongly effects the quality of the diffraction patterns and thus, the obtainable results. Dietrich et al. [27] described a preparation method based on vibration polishing using a silicon oxide suspension. It is claimed that an improvement of the EBSD pattern signals can be achieved compared with oxide and electro polishing methods. Based on experimental investigations evaluating the different approaches, it is concluded that vibration polishing outperforms the remaining methods and enables very levelled and largely undeformed surfaces, thus providing high preparation quality. Consequently, all specimens subjected to EBSD analysis are prepared according to the described method.

The EBSD system is integrated into a scanning electron microscope of the type Zeiss NEON 40EsB which is operated at $15 \mathrm{kV}$ with a $60-\mu \mathrm{m}$ aperture in high current mode. EBSD data sets are measured typically in regions of interest of $(50 \times 80) \mu \mathrm{m}^{2}$ with a sampling size of $100 \mathrm{~nm}$. The SiC particles appear brighter than the aluminium alloy matrix within the SE images. Thus, the SE signal can be used to separate the particles from the matrix for filtering the EBSD data sets. Subsequently, the EBSD data are subjected to a slight clean-up procedure comprising neighbour confidence index (CI) correlation and grain CI standardisation with a minimum confidence index of 0.1 . The parameters for grain size determination are set to $15^{\circ}$ tolerance angle and a minimum of three hits per grain.

Complementary to the described quantitative approaches, SEM images enable a qualitative description of the void formation and other surface imperfections on the generated surface. The tool flank wear is determined based on the assessment of SEM images.

\section{Results and discussion}

Subsequent to the cutting experiments, the flank wear land width of the applied tools was determined in a range of about 15 to $24 \mu \mathrm{m}$. These values are rather low compared with typically applied wear criteria $(\mathrm{VB}=0.3 \mathrm{~mm}$ ), emphasising the applicability of MCD as cutting material. However, at first, the influence of the cutting speed on the resulting surface structure is taken into consideration. Figure 9 shows the surface roughness depth $\mathrm{Rz}$ when applying different cutting speeds for both clearance angles.

The presented error bars indicate the fluctuations out of nine measurements in total, distributed over three specimens machined with the same combination of process parameters.

It emerges that the increase of the cutting speed from 100 up to $200 \mathrm{~m} / \mathrm{min}$ results in a decrease of the roughness values. One of the main reasons for that is assumed to be an increase of the temperature in the cutting zone when using 


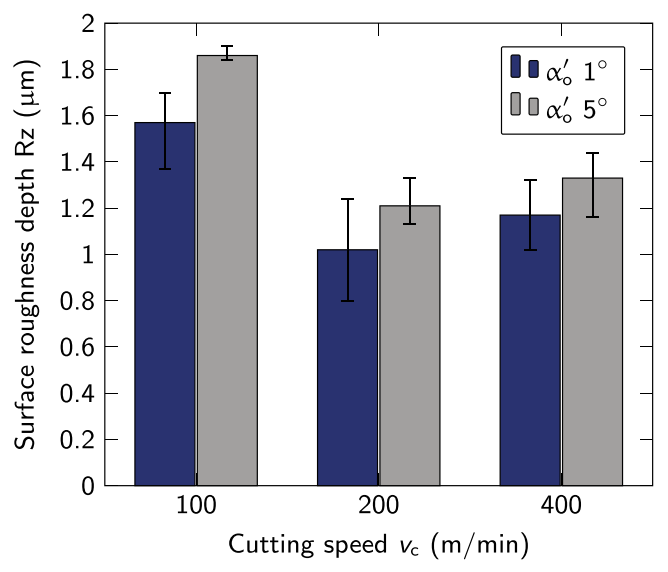

Fig. 9 Influence of the cutting speed $v_{\mathrm{c}}$ and the clearance angle of the minor cutting edge $\alpha_{\mathrm{o}}^{\prime}$ on the surface roughness depth $\mathrm{Rz}\left(f_{\mathrm{ax}}=2 \mathrm{~mm}\right.$, $\left.f_{\mathrm{z}}=0.2 \mathrm{~mm}, a_{\mathrm{p}}=0.2 \mathrm{~mm}, \gamma_{\mathrm{o}}^{\prime}=0^{\circ}\right)$

an increased cutting speed. Wang et al. [20] as well as Clauß, Nestler, and Schubert [23] drew similar conclusions when milling particle-reinforced AMCs. However, with a further increase of the cutting speed, the surface roughness values remain in a comparable range. On average, lower $\mathrm{Rz}$ values are achieved using a tool with a smaller clearance angle of the minor cutting edge.

In addition to the roughness values of the generated surfaces, the valley void volume $\mathrm{Vvv}$ is also influenced by the cutting speed applied. Figure 10 shows the resulting specific values of the volumetric parameter depending on the cutting speed and the clearance angle of the minor cutting edge.

The results indicate that an increase of the cutting speed from 100 up to $200 \mathrm{~m} / \mathrm{min}$ also benefits a reduced formation of surface imperfections, thus leading to reduced specific values of the valley void volume. Referring to this, the results presented by Clauß, Nestler, and Schubert [23] when milling an AMC with a CVD diamond-tipped tool and

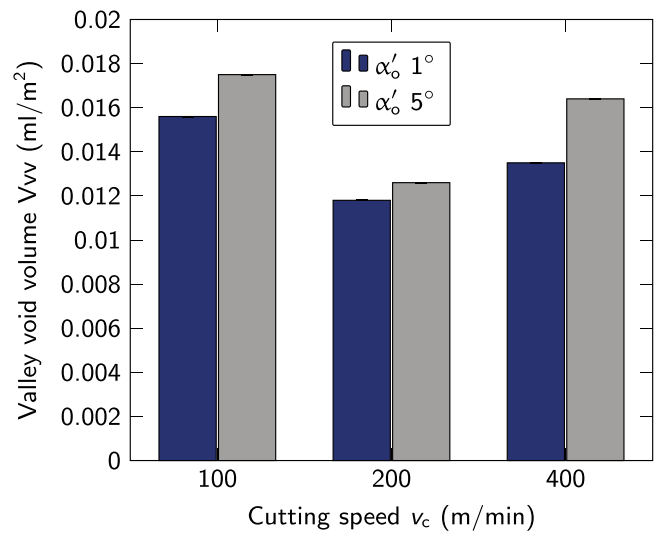

Fig. 10 Influence of the cutting speed $v_{\mathrm{c}}$ and the clearance angle of the minor cutting edge $\alpha_{\mathrm{o}}^{\prime}$ on the valley void volume $\mathrm{Vvv}\left(f_{\mathrm{ax}}=2 \mathrm{~mm}\right.$, $f_{\mathrm{z}}=0.2 \mathrm{~mm}, a_{\mathrm{p}}=0.2 \mathrm{~mm}, \gamma_{\mathrm{o}}^{\prime}=0^{\circ}$ ) different cutting speeds exhibited a comparable trend. In difference to the results in milling, a further increase of the cutting speed from 200 to $400 \mathrm{~m} / \mathrm{min}$ in turn milling results in increased Vvv values. Nonetheless, similar to the surface roughness values presented in Fig. 9, lower Vvv values are realised with the tool featuring a smaller clearance angle of the minor cutting edge. A more comprehensive insight into the formation of imperfections on the generated surface is provided using SEM imaging. Figure 11 shows the surfaces generated with a cutting speed of $100 \mathrm{~m} / \mathrm{min}$ and $200 \mathrm{~m} / \mathrm{min}$ as well as a clearance angle of the minor cutting edge of $1^{\circ}$.

Apparently, the generated surfaces incorporate deep voids in both cases. Depending on the number and depth of the voids, the valley void volume, as a characteristic value of the generated surface, is influenced. SEM images were used to provide qualitative statements on the generated surface. However, combined with the results presented in Fig. 10, it can be assumed that an increasing cutting speed up to a certain value decreases the formation of surface imperfections. One reason is seen in an increase of the cutting temperature and thus, a higher ductility of the matrix alloy.

Additionally, surfaces generated with different axial feeds of $1 \mathrm{~mm}, 2 \mathrm{~mm}$, and $3 \mathrm{~mm}$ are investigated. Figure 12 shows the determined surface roughness depths Rz.

It emerges that there is a comparably strong fluctuation of the achieved roughness values. Thus, independent of the actually applied feed or tool geometry, the specific values are in a similar range. However, on average, lower roughness values are achieved with a smaller clearance angle compared with the larger clearance angle investigated. Furthermore, there is a slight increase of the average roughness values with an increase of the axial feed applying a clearance angle of $5^{\circ}$. In difference to that, an increased axial feed combined with a clearance angle of $1^{\circ}$ does not lead to significant changes of the average values.

One of the main reasons for that is seen in the heterogeneous microstructure of the machined material illustrated according to Fig. 2. As a result of stochastic particle fracture and pull-out during the cutting process, strong fluctuations in the surface structure appear. Accordingly, there is a significantly stronger influence of the resulting surface imperfections on the roughness profile characteristics compared with the influence of the process kinematics. For the reason of the same mechanism, the averaged roughness values are increased due to the resulting strong fluctuation of the measured values. Eventually, the expected trend resulting from the kinematic influence of an increased axial feed is less distinct. However, an additional aspect can be seen with a reduced fluctuation of the roughness values with increased axial feed. This can be attributed to an increased undeformed chip thickness leading to a more strongly pronounced boundary layer of the generated surface. Work 
Fig. 11 Imperfections on the generated surface for different cutting speeds. (a) $100 \mathrm{~m} / \mathrm{min}$. (b) $200 \mathrm{~m} / \mathrm{min}\left(f_{\mathrm{ax}}=2 \mathrm{~mm}\right.$, $f_{\mathrm{z}}=0.2 \mathrm{~mm}, a_{\mathrm{p}}=0.2 \mathrm{~mm}$, $\left.\alpha_{\mathrm{o}}^{\prime}=1^{\circ}, \gamma_{\mathrm{o}}^{\prime}=0^{\circ}\right)$
Plasticised matrix alloy

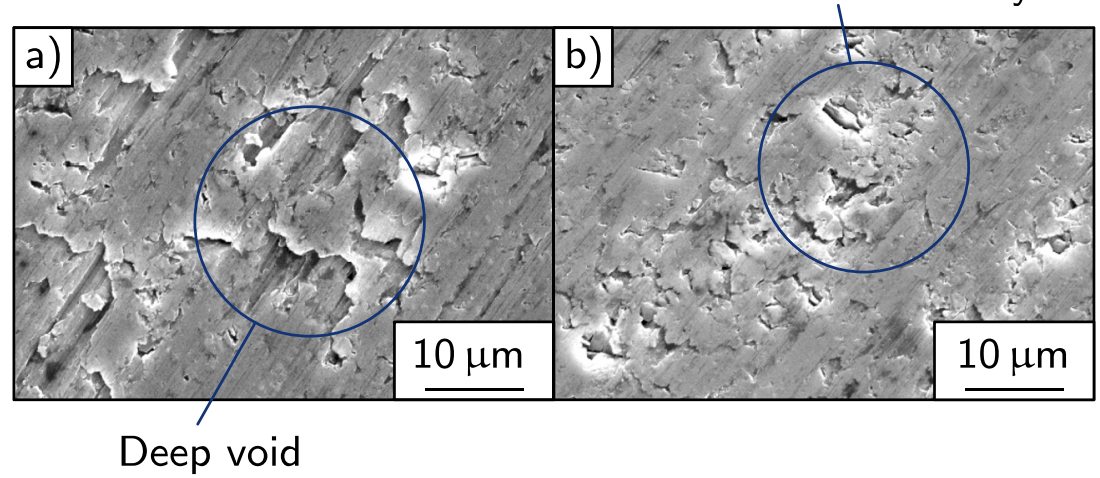

hardening benefits the resistance against particle pull-out, thus leading to less fluctuating surface characteristics.

Figure 13 presents the achieved specific values for the valley void volume using different axial feeds and tools with distinct clearance angles.

It is shown that the values of the valley void volumes of the generated surfaces produced with a tool exhibiting a clearance angle of $5^{\circ}$ vary strongly when applying different values of the axial feed. No clear trend can be identified, which is primarily attributed to a random tool-particle interaction, reduced stresses in the tertiary cutting zone, and, thus reduced smoothing effects compared with the tool with a lower clearance angle. In difference to that, the valley void volume increases more significantly and steadily with a rise of the axial feed values for the tool with a clearance angle of the minor cutting edge of $1^{\circ}$. However, the most significant difference is identified when comparing the distinct clearance angles using the lowest axial feed of $1 \mathrm{~mm}$.

This effect is mainly attributed to the increased plastic deformation in the tertiary shear zone at the flank face when using the tool with a lower clearance angle of the minor

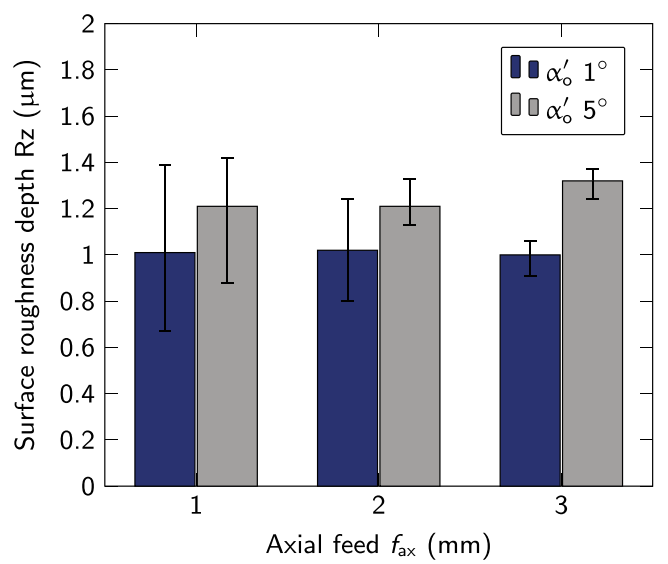

Fig. 12 Influence of the axial feed $f_{\mathrm{ax}}$ and the clearance angle of the minor cutting edge $\alpha_{0}^{\prime}$ on the surface roughness depth $\mathrm{Rz}$ $\left(v_{\mathrm{c}}=200 \mathrm{~m} / \mathrm{min}, f_{\mathrm{z}}=0.2 \mathrm{~mm}, a_{\mathrm{p}}=0.2 \mathrm{~mm}, \gamma_{\mathrm{o}}^{\prime}=0^{\circ}\right)$ cutting edge. It is stated that the applied cutting speed of $200 \mathrm{~m} / \mathrm{min}$ provides a sufficient increase of the temperature in the cutting zone and thus, an appropriate ductility of the matrix alloy benefiting the void closure when using the tool with the lower clearance angle due to stronger smoothing effects. Additionally, the influence of a variation of the feed per tooth on the surface structure is investigated. Figure 14 shows the achieved values for the surface roughness depth.

An increase of the feed per tooth from 0.1 to $0.2 \mathrm{~mm}$ involves increased surface roughness values. The findings of Bian et al. [25] show a similar effect of an increased feed per tooth when milling AMCs with MCD-tipped tools. Referring to the presented averaged values in turn milling, with a further increase of the feed per tooth up to $0.3 \mathrm{~mm}$, there is no significant change in the $\mathrm{Rz}$ values when applying the tool with a clearance angle of $1^{\circ}$. In case of the tool with a $5^{\circ}$ clearance angle, there is a clear trend of the averaged roughness values increasing with higher feed per tooth. Regarding the $\mathrm{Rz}$ values when using the tool with a clearance angle of the minor cutting edge of $5^{\circ}$, in most cases, there is a reduced fluctuation of the specific values compared with the tool with the lower clearance angle. The machining with a feed per tooth of $0.1 \mathrm{~mm}$ results in

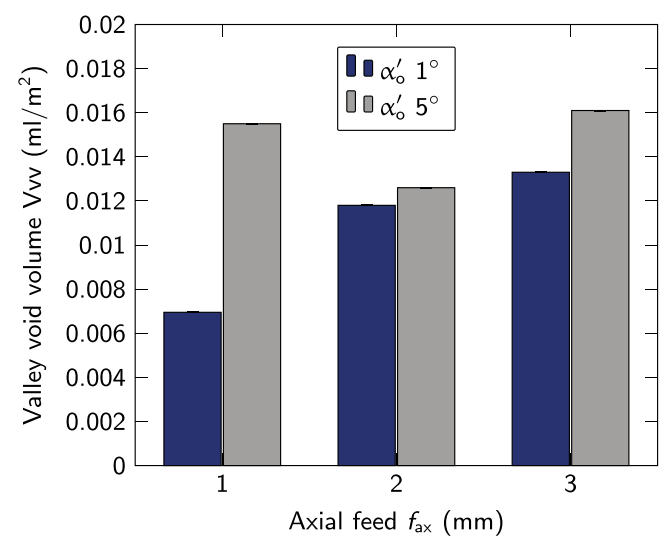

Fig. 13 Influence of the axial feed $f_{\mathrm{ax}}$ and the clearance angle of the minor cutting edge $\alpha_{\mathrm{o}}^{\prime}$ on the valley void volume $\mathrm{Vvv}\left(v_{\mathrm{c}}=200 \mathrm{~m} / \mathrm{min}\right.$, $f_{\mathrm{z}}=0.2 \mathrm{~mm}, a_{\mathrm{p}}=0.2 \mathrm{~mm}, \gamma_{\mathrm{o}}^{\prime}=0^{\circ}$ ) 


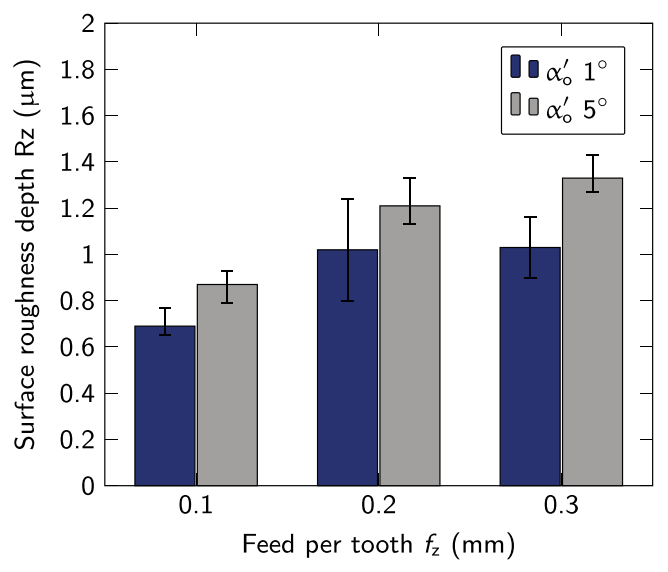

Fig. 14 Influence of the feed per tooth $f_{\mathrm{Z}}$ and the clearance angle of the minor cutting edge $\alpha_{0}^{\prime}$ on the surface roughness depth Rz $\left(v_{\mathrm{c}}=200 \mathrm{~m} / \mathrm{min}, f_{\mathrm{ax}}=2 \mathrm{~mm}, a_{\mathrm{p}}=0.2 \mathrm{~mm}, \gamma_{\mathrm{o}}^{\prime}=0^{\circ}\right)$

comparably low fluctuations for both clearance angles in the investigated range. Nonetheless, an increase of the feed per tooth combined with a clearance angle of $5^{\circ}$ leads to higher values of the surface roughness depth compared with the tool with the lower clearance angle. The comparably strong fluctuations are primarily attributed to a strong influence of the emerging porosity on the generated surface.

Figure 15 shows the valley void volume resulting from turn milling with different values of the feed per tooth.

Comparable wtih the surface roughness values, the most significant change is found with an increase of the feed per tooth from 0.1 to $0.2 \mathrm{~mm}$. With a further increase of the feed per tooth, there is an ongoing but reduced rise of the valley void volume indicating a digressive trend. In general, lower Vvv values result from turn milling with the tool exhibiting a clearance angle of $1^{\circ}$. This is presumed to be a result of an increased plastic deformation in the tertiary shear zone, benefiting void closure immediately after cutting. Additionally, the lowest feed per tooth in the

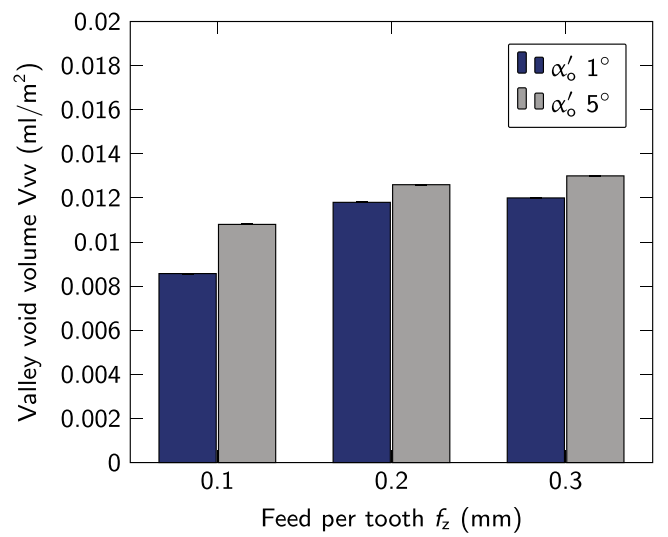

Fig. 15 Influence of the feed per tooth $f_{\mathrm{Z}}$ and the clearance angle of the minor edge $\alpha_{\mathrm{o}}^{\prime}$ on the valley void volume $\mathrm{Vvv}\left(v_{\mathrm{c}}=200 \mathrm{~m} / \mathrm{min}\right.$, $f_{\mathrm{ax}}=2 \mathrm{~mm}, a_{\mathrm{p}}=0.2 \mathrm{~mm}, \gamma_{\mathrm{o}}^{\prime}=0^{\circ}$ )

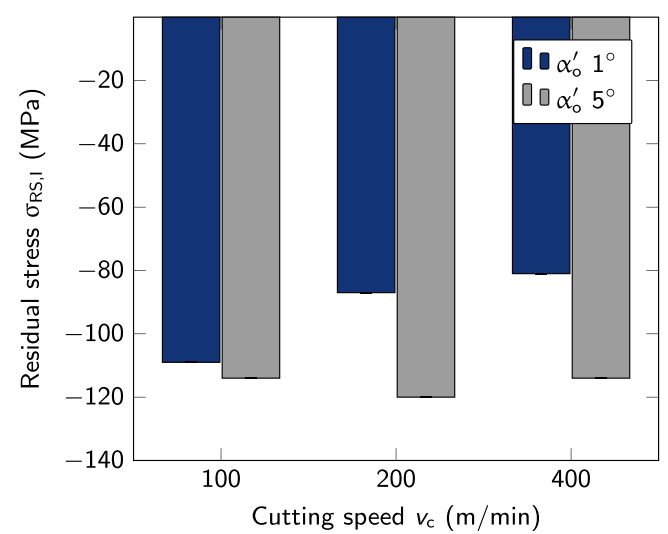

Fig. 16 Influence of the cutting speed $v_{\mathrm{c}}$ and the clearance angle of the minor cutting edge $\alpha_{\mathrm{o}}^{\prime}$ on the first principal residual stress $\left(f_{\mathrm{ax}}=2 \mathrm{~mm}\right.$, $\left.f_{\mathrm{z}}=0.2 \mathrm{~mm}, a_{\mathrm{p}}=0.2 \mathrm{~mm}, \gamma_{\mathrm{o}}^{\prime}=0^{\circ}\right)$

investigated range results in a lesser valley void volume for both tool geometries applied in the experiments.

In addition to the investigations referencing the surface structure, the physical properties of the generated surfaces are considered. Figure 16 presents the residual stress state of the surface layer depending on the cutting speed and the clearance angle of the minor cutting edge applied.

Generally, it is found that turn milling results in the generation of compressive residual stresses when machining the AMC. However, an increased cutting speed leads to decreased absolute values of the compressive residual stresses, when applying a tool with a clearance angle of $1^{\circ}$. This is mainly attributed to an increased influence of thermal effects in the cutting zone. In contrast to that, there is no significant influence of the cutting speed when using tools with a clearance angle of $5^{\circ}$. Nonetheless, the strongest compressive residual stresses in the surface layer are achieved using a tool with a clearance angle of $5^{\circ}$ and a cutting speed of $200 \mathrm{~m} / \mathrm{min}$. It is stated that there must be a limited range of process parameters in which the compressive residual stresses can be adjusted. Accordingly, certain parameter combinations could lead to excessive stress in the cutting zone. Once critical material parameters are exceeded, flow or disruption effects occur in the microstructure benefiting degradation of compressive residual stresses.

Subsequently, the influence of the axial feed and the feed per tooth on the residual stress state is investigated. In this context, the application of the lower clearance angle of $1^{\circ}$ is focused. A reduced clearance angle is assumed to provide a stronger influence on the stress regime in the tertiary cutting zone and the most significant effect of the resulting residual stress state. The effect of different values of the axial feed on the residual stress state is illustrated in Fig. 17.

In the investigated range, the lowest value of the axial feed results in a stronger compressive residual stress 


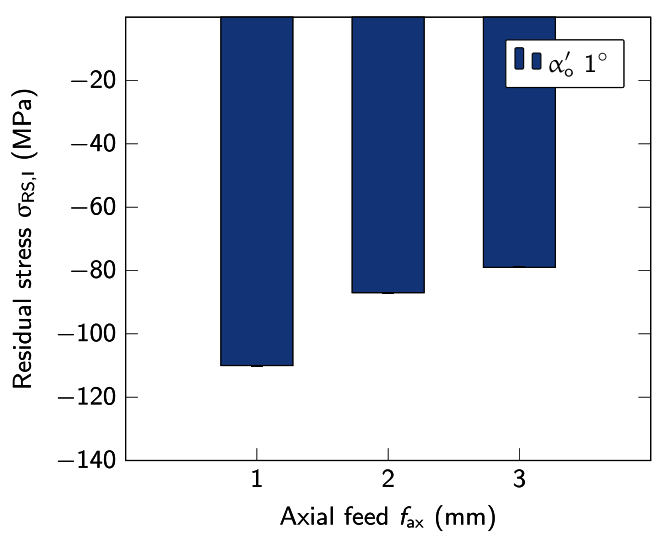

Fig. 17 Influence of the axial feed $f_{\text {ax }}$ on the first principal residual stress $\left(v_{\mathrm{c}}=200 \mathrm{~m} / \mathrm{min}, f_{\mathrm{z}}=0.2 \mathrm{~mm}, a_{\mathrm{p}}=0.2 \mathrm{~mm}, \gamma_{\mathrm{o}}^{\prime}=0^{\circ}\right)$

compared with the investigated medium or high values. One possible reason for that is seen in the number of tool paths, necessary to generate the surface, which increases with a reduced axial feed. Referring to that and according to Fig. 13 with a clearance angle of the minor cutting edge of $1^{\circ}$, a lower porosity is achieved. Consequently, the degradation of residual stresses in the surface layer is reduced and higher absolute values of the compressive residual stresses can be sustained.

Eventually, the influence of the feed per tooth on the residual stress state is taken into consideration presented in Fig. 18.

It is indicated that the feed per tooth only provides a minor influence in the investigated range. Increased values of $f_{\mathrm{z}}$ result in slightly decreased absolute values of the compressive residual stresses. This could be attributed to a higher valley void volume according to Fig. 15, benefiting stress degradation in the surface layer.

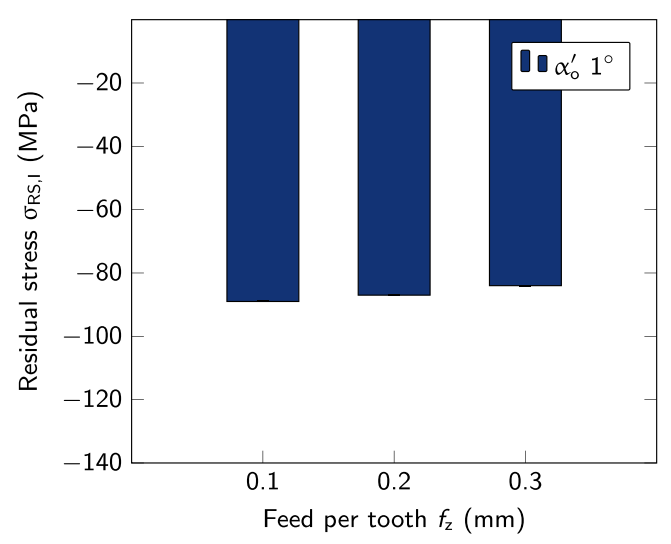

Fig. 18 Influence of the feed per tooth $f_{z}$ on the first principal residual stress $\left(v_{\mathrm{c}}=200 \mathrm{~m} / \mathrm{min}, f_{\mathrm{ax}}=2 \mathrm{~mm}, a_{\mathrm{p}}=0.2 \mathrm{~mm}, \gamma_{\mathrm{o}}^{\prime}=0^{\circ}\right)$
However, another main point of interest is seen within the mechanisms that influence the physical properties of the generated surfaces, thus resulting in a certain residual stress state after machining. As a contribution to a better understanding of these mechanisms, the grain sizes and the assigned proportions in the bulk material and the surface layer are subjected to investigations, based on EBSD analysis.

In a narrow region bordering the generated surface, a typical drop of about $10 \%$ of the averaged EBSD pattern quality of the matrix is observed. Since this drop indicates lattice deformation, that zone with a width of around $10 \mu \mathrm{m}$ is presumed to be influenced by the machining process. Accordingly, the grain size distribution for a $(10 \times 50) \mu \mathrm{m}^{2}$ wide region bordering the surface layer is estimated and compared with the grain size distribution of a $(30 \times 50) \mu \mathrm{m}^{2}$ wide inner region of the measured area in the bulk material. The $(10 \times 50) \mu \mathrm{m}^{2}$ evaluation field on purpose focuses a smaller area addressing only the surface near layers in a narrow band to determine the effects of the cutting process. In difference to that, the bulk material in the state after manufacturing and prior to machining is characterised using $\mathrm{a}(30 \times 50) \mu \mathrm{m}^{2}$ evaluation field to respect possible inherent variations in the microstructure that can appear with AMCs in order to obtain more representative values. Grains are determined by a tolerance angle of $15^{\circ}$, thus considering only high angle grain boundaries.

According to Figs. 19 and 20, the grain sizes as well as their proportions are illustrated for the bulk material and the surface layer for two different cutting speeds. The investigated area of the bulk material is located several millimetres from the surface layer, so that the material provides the unaffected microstructure.

Investigating the influence of the machining process, specimens with the lowest and the highest cutting speed in the investigated range are subjected to EBSD analysis.

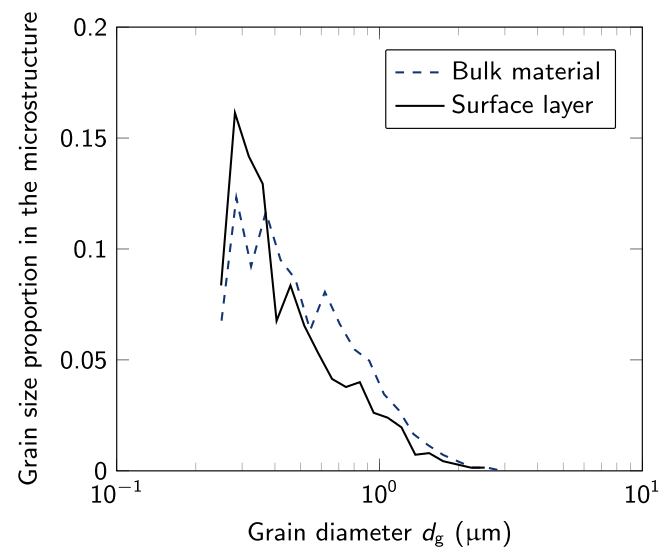

Fig. 19 Grain size proportion in the bulk material and the surface layer $\left(v_{\mathrm{c}}=100 \mathrm{~m} / \mathrm{min}, f_{\mathrm{ax}}=2 \mathrm{~mm}, f_{\mathrm{z}}=0.2 \mathrm{~mm}, a_{\mathrm{p}}=0.2 \mathrm{~mm}, \alpha_{\mathrm{o}}^{\prime}=1^{\circ}\right.$, $\left.\gamma_{\mathrm{o}}^{\prime}=0^{\circ}\right)$ 


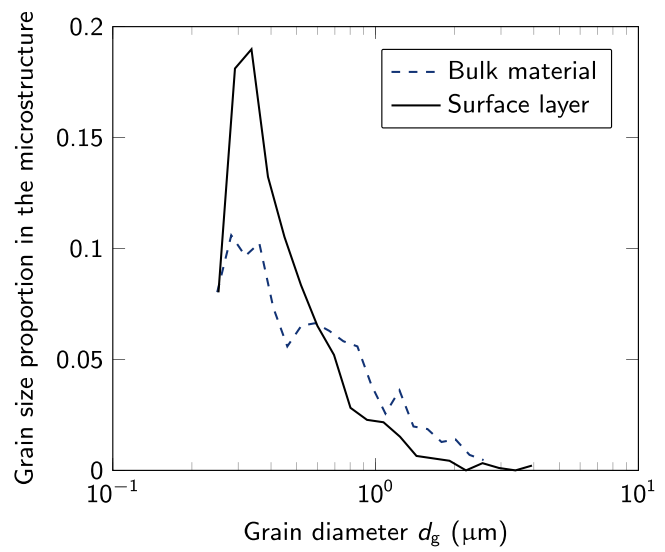

Fig. 20 Grain size proportion in the bulk material and the surface layer $\left(v_{\mathrm{c}}=400 \mathrm{~m} / \mathrm{min}, f_{\mathrm{ax}}=2 \mathrm{~mm}, f_{\mathrm{z}}=0.2 \mathrm{~mm}, a_{\mathrm{p}}=0.2 \mathrm{~mm}, \alpha_{\mathrm{o}}^{\prime}=1^{\circ}\right.$, $\left.\gamma_{0}^{\prime}=0^{\circ}\right)$

The remaining parameters are kept unchanged according to Table 2. The intention is to create a strong contrast between the considered values of cutting speed, to more clearly identify possible effects. Subsequently, the grain size distributions comparing the microstructure of the bulk material and the surface layer are examined.

First of all, the analyses indicate that the grain size distributions for the bulk material of both specimens present comparable characteristics. However, there is a certain variation between the graphs, as slight fluctuations of the microstructure can even occur within the same batch of a material.

Secondly, it emerges that the surface layer of the generated surface, representing the state after the machining, in both cases and independently of the applied cutting speed provides a larger proportion of grains with smaller diameters.

However, the parameter combination with a higher cutting speed of $400 \mathrm{~m} / \mathrm{min}$ (Fig. 20) compared with the process with a lower of both cutting speeds of $100 \mathrm{~m} / \mathrm{min}$ results in a larger proportion of fine grains for comparable grain diameters. In the range of 0.3 to $0.4 \mu \mathrm{m}$, the fractions of particles providing the assigned sizes are almost increased to about $200 \%$ compared with the microstructure of the bulk material, representing almost $20 \%$ of the microstructure in the surface layer in total. In difference to that, in the microstructure of the surface layer machined with a cutting speed of $100 \mathrm{~m} / \mathrm{min}$ (Fig. 19), only about $16 \%$ of the grains provide a diameter in a comparable range. The presented result is mainly attributed to mechanical effects in the cutting zone that benefit grain refinement with a high cutting speed. However, taking the presented data into consideration, a refinement of the microstructure as a result of the machining process appears evidently.

\section{Summary and conclusions}

Based on a fractional experimental design, cutting tests in turn milling were conducted using single-edged MCDtipped tools. In the experiments, the influence of the cutting parameters in turn-milling such as:

- cutting speed $v_{\mathrm{c}}$,

- axial feed $f_{\text {ax }}$,

- and the feed per tooth $f_{\mathrm{Z}}$

are investigated. In addition, two different types of tools were applied for the turn milling tests providing different clearance angles of the minor cutting edge $\alpha_{0}^{\prime}$ of $1^{\circ}$ and $5^{\circ}$. The results referring to the surface microstructure indicate that:

- an increase of the cutting speed benefits decreased surface roughness values $\mathrm{Rz}$ as well as a reduced valley void volume $\mathrm{Vvv}$.

- the void closure is supported by a low clearance angle of the minor cutting edge.

- there is only a minor influence of the axial feed on the surface roughness.

- when applying the lowest axial feed, there is a significant difference between the values of the valley void volume generated with different clearance angles.

- the feed per tooth influences the surface roughness values strongly in the range from 0.1 to $0.2 \mathrm{~mm}$.

In addition to the surface structure, the residual stress state of the generated surfaces was considered using X-ray diffraction analyses. The evaluations according to $\sin ^{2} \psi$ method show that:

- an increased cutting speed results in decreased absolute values of the compressive residual stresses, if a tool with a clearance angle of $1^{\circ}$ is applied.

- when applying a tool with a clearance angle of $5^{\circ}$, there is a less significant influence of the cutting speed.

- the strongest compressive residual stresses are achieved with the tool providing a $5^{\circ}$ clearance angle of the minor cutting edge and a cutting speed of $200 \mathrm{~m} / \mathrm{min}$.

- an increase of the axial feed results in reduced compressive residual stresses while there is no significant influence of the feed per tooth when using a tool with a clearance angle of $1^{\circ}$.

Eventually, the microstructure of the surface layer was investigated based on EBSD analyses. The evaluation of the grain size proportions reveals that:

- a grain refinement of the matrix microstructure occurs in the surface layer.

- $\quad$ in the investigated range, the refinement is benefited by an increased cutting speed. 
Concluding the research, a more comprehensive insight into turn milling of AMCs is provided. The findings can be transferred to machining of non-circular parts. The potentials of a modified tool geometry are indicated. Further investigations should address the underlying mechanisms of the interactions between cutting parameters and porosity as well as the influence of mechanical and thermal effects within the surface layer.

Funding This study was funded by the German Research Foundation within the framework of the Collaborative Research Centre SFB 692 (Deutsche Forschungsgemeinschaft, DFG, grant number 14208545).

\section{Compliance with Ethical Standards}

Conflict of interests The authors declare that they have no conflict of interest.

Open Access This article is distributed under the terms of the Creative Commons Attribution 4.0 International License (http:// creativecommons.org/licenses/by/4.0/), which permits unrestricted use, distribution, and reproduction in any medium, provided you give appropriate credit to the original author(s) and the source, provide a link to the Creative Commons license, and indicate if changes were made.

\section{References}

1. Singh I, Chaitanya S, Kumar R (2014) In: Davim JP (ed) Metal matrix composites: materials, manufacturing and engineering. 1st. De Gruyter, Berlin, Germany, chap 6: Material removal processes for metal matrix composites, pp 141

2. Schmidt A et al (2018) Particle-reinforced aluminium matrix composites (AMCs) - selected results of an integrated technology, user, and market analysis and forecast. Metals 8(143):1-11

3. Di Ilio A, Paoletti A (2012) In: Davim JP (ed) Machining of metal matrix composites. 10th. Springer, London, chap 3: Machinability aspects of metal matrix composites, pp 63

4. Hung NP et al (1995) Machinability of cast and powder-formed aluminium alloys reinforced with $\mathrm{SiC}$ particles. J Mater Process Technol 48(1-4):291-297

5. Yanming Q, Zehua Z (2000) Tool wear and its mechanism for cutting SiC particle-reinorced aluminium matrix composites. J Mater Process Technol 100(1-3):194-199

6. Ding X, Liew WYH, Liu XD (2005) Evaluation of machining performance of MMC with PCBN and PCD tools. Wear 259:1225-1234

7. Collins JL, Cook MW (2000) Machining MMCs with diamond tools. In: Tribology 2000 - Plus, 12th international colloquium, Nr. 3 , pp 1837-1853

8. Cooper $\mathrm{N}$ et al (2007) Machining of metal matrix composites using PCD, natural diamond, single crystal CVD and p CVD diamond. Industrial Diamond Review - IDR 67(3):34-38
9. Bejjani R et al (2011) Laser assisted turning of titanium metal matrix composite. CIRP Annals 60:61-64

10. Dandekar RC, Shin YC (2013) Experimental evaluation of laser-assisted machining of silicon carbide particle-reinforced aluminium matrix composites. Int J Adv Manuf Technol 66:16031610

11. Przestacki D (2014) Conventional and laser assisted machining of composite A359/20SiCp. Procedia CIRP 14:229-233

12. Przestacki D, Jankowiak M (2014) Surface roughness analysis after laser assisted machining of hard to cut materials. J Phys Conf Ser 483:1-7

13. Nestler A, Schubert A (2014) Surface properties in ultrasonic vibration assisted turning of particle reinforced aluminium matrix composites. Procedia CIRP 13:125-130

14. Xiang DH et al (2010) Study on cuting force and tool wear of high volume Sic/al MMCs with ultrasonic vibration high speed milling. Key Eng Mater 455:264-268

15. Zhi X, Xiang D, Deng J (2013) Research on high volume fraction $\mathrm{SiC}_{p} / \mathrm{Al}$ removal mechanism under condition of ultrasonic vertical vibration. Appl Mech Mater 373-375:2038-2041

16. Dabade UA et al (2007) Surface finish and integrity of machined surface on $\mathrm{Al} / \mathrm{SiC}_{p}$ composites. J Mater Process Technol 192193:166-174

17. Bushan RK, Kumar S, Das S (2010) Effect of machining parameters on surface roughness and tool wear of $7075 \mathrm{Al}$ alloy SiC composite. Int J Adv Manuf Technol 50(5-8):459-469

18. Ge Y, Xu J, Fu Y (2011) Experimental study on high-speed milling of SiCp/Al composites. Adv Mater Res 291-294:725-731

19. Dong $G$ et al (2013) The research of effect of cutting parameters on machined surface defects in high-speed milling of SiCp/Al composites. Key Eng Mater 589-590:245-251

20. Wang T et al (2013) Surface integrity of high speed milling of $\mathrm{Al} / \mathrm{SiC} / 65_{p}$ aluminum matrix composites. Procedia CIRP 8:475480

21. Schubert A et al (2010) Finishing of aluminium based light weight materials - influence on surface properties. In: Proceedings of the ICMC, pp 447-464

22. Schubert A, Nestler A (2011) Enhancement of surface integrity in turning of particle reinforced aluminium matrix composites by tool design. Protein Eng 19:300-305

23. Clauß B, Nestler A, Schubert A (2016) Investigation of surface properties in milling of $\mathrm{SiC}$ particle reinforced aluminium matrix composites (AMCs). Procedia CIRP 46:480-483

24. Ge YF et al (2008) Workpiece surface quality when ultra-precision turning of $\mathrm{SiCp} / \mathrm{Al}$ composites. J Mater Process Technol 203(13): $166-175$

25. Bian $\mathrm{R}$ et al (2013) Precision milling of high volume fraction $\mathrm{SiC}_{p} / \mathrm{Al}$ composites with monocrystalline diamond end mill. Int $\mathrm{J}$ Adv Manuf Technol 71:411-419

26. Schubert A, Funke R, Nestler A (2011) Influence of kinematics on the surface integrity in orthogonal turn-milling of aluminium matrix composites. In: Spann $\mathrm{H}$ et al (eds) Proceedings of the 11th EUSPEN, vol 2, pp 480-483

27. Dietrich D et al (2008) EBSD And STEM on aluminum alloys subjected to high-degree plastic deformation. Practical Metallography 48(3):136-150

Publisher's note Springer Nature remains neutral with regard to jurisdictional claims in published maps and institutional affiliations. 